Article

\title{
Participatory Multi-Criteria Assessment of Forest Planning Policies in Conflicting Situations: The Case of Tenerife
}

\section{Montserrat Acosta ${ }^{1}$ and Serafin Corral ${ }^{2, *}$}

1 Department of Techniques and Projects in Engineering and Architecture, University of La Laguna, Canary Islands 38200, Spain; E-mail: mmacosta@ull.edu.es

2 CIBICAN-Department of Applied Economics and Qualitative Methods, University of La Laguna, Canary Islands 38200, Spain

* Author to whom correspondence should be addressed; E-Mail: scorral@ull.edu.es; Tel.: +34-9223-17009; Fax: +34-9223-17855.

Academic Editors: Rodney J. Keenan and Eric J. Jokela

Received: 3 August 2015 / Accepted: 29 October 2015 / Published: 3 November 2015

\begin{abstract}
Sustainable forest planning should involve the participation of stakeholder communities in the decision-making process. This participation can help avoid the possible rejection of new planning measures. In this paper, the decision-making process to implement regulations on the use of forest tracks on the island of Tenerife (Canary Islands, Spain) is analyzed. In recent years, the number of people using the island's forest environments has notably increased, leading to conflicts between different users of the tracks; as a result, the Island Council of Tenerife is working on regulating these pathways. This paper describes the framing analysis, design, and implementation of a participatory multi-criteria approach to explore, together with stakeholders, the best policy alternatives related to forest planning and management issues of forest track use. To do this, a set of tools has been developed, consisting of institutional analysis, participatory methods, and multi-criteria assessment techniques.
\end{abstract}

Keywords: forest policy alternatives; participatory multi-criteria assessment; political conflict; forest system uncertainty; forest track use 


\section{Introduction}

One of the most prominent features of public policy processes is their social nature. Policy issues cannot be analyzed in isolation from the social context in which they occur [1]. They are affected by different perceptions, perspectives, opinions, knowledge, and interests. As Lindblom [2] argues, there is a deep and persistent unwillingness in Western culture to acknowledge the difficulties arising from the world's complexity and humans' modest cognitive abilities. Unless political action is adjusted to take into account the fact that complex problems cannot be understood fully, policy-making will fare much worse than it needs to. Generally, in decision-making processes, decision-makers rank a set of decision alternatives and choose the best according to their preferences [3]; however, this is probably not the best way of approaching complex decision-making scenarios.

Today's forestry governance, in which multiple criteria, functions, and stakeholders with conflicting interests are involved, calls for more flexible and versatile decision-making processes than can be achieved using "traditional" simulation and optimization tools alone.

In recent years, several authors have written about the inherent complexity of environmental processes [4-6], the complexity of forest resource planning [7-9], and the importance of the involvement of stakeholders in these processes [10-12].

In Tenerife, a research project on the use of the island's forest roads/tracks is being performed to establish a participatory framework for decision-making processes and to explore the results of these participatory activities. In recent years, the influx of people to the island's forest environment has notably increased. The growth in the number of visits is due to a variety of reasons (e.g., doing adventure sports, escaping from stressful urban areas, and developing forest-related economic activities). Moreover, some of the most recent users go to forested areas to do motorized sports, creating complicated issues in an already complicated planning process for the use of forest tracks. In fact, more and more conflicts are arising among the users of these pathways. Consequently, the Island Council of Tenerife (the administrative body responsible for forest planning and management) is working on regulating the use of forest tracks from a bureaucratic perspective, with scarce citizen participation in the elaboration process of these new regulations. The first draft of these regulations was not well received by the population of the island because it implied some constraints on access and on activities allowed in the island's forests and mountains. This was considered a radical change, since forest access and activities had never been regulated before.

This paper conducts a framing analysis and designs and implements a participatory multi-criteria approach to explore, with stakeholders, possible policy alternatives for forest planning and management of track use where opposite interests are evident. This integrated analysis follows works carried out by Corral Quintana, De Marqui et al., and Paneque et al. ([13-15]), among others, on approaches based on the relevance of extended participatory assessments [16,17]. In this paper, the key methodological aspects and major findings will be discussed. 


\section{Case Study}

\subsection{Framing}

This research has been carried out on the island of Tenerife (Canary Islands, Spain). Tenerife has a surface area of $2034.38 \mathrm{~km}^{2}$, of which $990 \mathrm{~km}^{2}$ are protected natural areas $(48.6 \%$ of the total surface area). It is worth mentioning that $22.9 \%$ of this area corresponds to the Corona Forest Nature Park [18]. This covers an area of 46,612.9 hectares, distributed among 17 municipalities [19]. The entire area of the Park is considered an Area of Ecological Sensitivity according to Law 11/1990 (13 July 1990), on the Prevention of Ecological Impacts [20].

Over the years, the local population has changed its use of the island's forest, reducing its exploitation for economic inputs, while gradually increasing the need for areas for leisure activities. Thus, García Mesa ([21]) highlights that between 1950 and 1960, the banana sector required the pine needles from the forest to protect bananas during transport. It was also common to use the forest to provide wood for fuel until the 1970s, when demand declined with the arrival of butane and the abandonment of farming. Nowadays, the forest has become a place for recreation, where sporting and educational activities are carried out instead of the traditional practices of providing raw materials. However, to do any activity in the forest, it is necessary to use the forest's roads/tracks.

\subsection{Forest Planning in Tenerife: A Complex Issue}

Currently, the existing forest tracks and roads of Tenerife are used to move around the forest for several different purposes such as access to water galleries and private farms - as part of the forest easement rights - as well as for fire prevention and extinction activities. Public and private vehicles are used to gain access for management and conservation work, use of forest resources, hunting-related activities, and other activities allowed within the scope of forest regulations (for example, research, sports events, and military maneuvers).

According to Quirantes González et al. [22], the majority of people who visit forests come from urban areas and are attracted by the natural, ecological, and scenic characteristics of these places. It is worth noting that not only local residents but also tourists to Tenerife use the forests. In addition, there are several annual pilgrimages through the forests. (For instance, in August, thousands of pilgrims from towns and villages on the island walk through the countryside to the town of Candelaria, with a resulting impact on the landscape and forests.) Despite being encouraged to use the tracks, a substantial number of pilgrims abandon the paths, and adjacent forest areas are consequently affected.

The increase in the number of visitors to forest areas has also involved a significant rise in the use of motorized means of transport, with a current rate of 4500 permits per year and annual growth rate of $20 \%$. However, Tenerife does not have a mechanism to control vehicle access to the forest environment of Tenerife. There is only information about the number of special vehicles requesting permission to access the forest tracks of the island (see Table 1), so the figure of 4500 permits only indicates the number of special vehicles and not the total number of vehicles passing through forests. This traffic has caused deterioration in the land surface, resulting not only in environmental degradation but also in a substantial increase in maintenance costs according to the Tenerife's Island Government, which is the body responsible for the forest planning and management on the island [23]. 
This growing traffic led to the implementation of a forest traffic regulation aimed at specifying a network of tracks and at placing restrictions on the circulation of recreational vehicles. (These restrictions are regulated through Resolution R0000319624 of 14 April 2011 [23]). This regulation dates back to 2006, when Spain approved the "Ley de montes" (Law for hills and forests) 10/2006. This Law prohibited motor vehicle traffic along forest tracks with some exceptions (easement rights, agro-forestry management, and fire monitoring and extinguishing by public services).

This measure led to a great deal of criticism from the island's population, who felt that the government had "put gates" on the forest. These regulations have divided local opinion between those who consider it a violation of their rights of use and those who completely support them. Thus, the requirement that vehicles with specific characteristics (Table 1) apply for permits to transit the forest - when previously they were able to do so without any restrictions - has upset a large sector of the population. On the other hand, these measures have been supported by forest users that do not use vehicles, as it has helped to reduce noise and has improved the quality of visits, as well as safety.

Table 1. Traffic regulations on forest tracks.

Vehicles that Can Be Used on the Network of Tracks for Recreational Use:
Without permit:
Four-wheel drive vehicles — private cars and vans that have four-wheel drive and
whose weight is less than 3.5 metric tons.
Sports Utility Vehicles (SUV).
Trail motorbikes.
They should have mixed tires whose tread should be equal to or less than $10 \mathrm{~mm}$.
With permit (limited to a daily quota of 150 vehicles):
Motorcycles equipped as trail, enduro, or cross.
Quad bikes with handlebar steering.
Four-wheel drive vehicles with tread between 10 and 15 mm.
Prohibited vehicles:
Those whose tires or tracks are equal to or more than 15 mm or wider than 34 inches.

Source: [23].

The planning for the use of forest tracks is complex, not only due to the number of people with different and conflicting interests (economic, environmental, and social) who want access to forests, but also because of their increasing number. In addition, there are aspects like the instability of these forest environments, which are often in continual change. The design and application of an appropriate methodology able to deal with all these aspects will be discussed in the following sections.

\section{Literature and Method: A Participatory Multi-Criteria Framework for Forest Planning Issues}

As mentioned above, forest resource planning and management is a complex social and political issue mainly due to the multiplicity of dimensions (economic, environmental, and social) involved in the decision-making process. (Numerous authors have commented on the existence of uncertainty in forest management. For a detailed discussion, see, for instance, [24-28].) Thus, the uncertainty regarding the consequences of alternative policy choices, the conflict between contradictory values, and the multiplicity of people concerned about policy decisions all mean that the use of other 
decision-making tools is required [16]. The joint use of multi-criteria analysis (MCA) with participatory approaches (PA) (Several studies dealing with participation techniques and processes have been carried out with regard to natural resources management $[13,14,29,30]$ and in forestry decision-making $[10,31,32]$ ) has turned out to be of paramount importance for forestry issues [8]. The combination of social techniques with MCA (Mendoza and Martins [33] carried out a review of MCDA methods that have been applied to processes related to natural resources and forests, establishing a classification of MCA methods based on a previous work of Belton and Stewart [34]) ones improves the understanding of the results from an analysis and clarifies the positions of the stakeholders involved in the process. These methods integrate formal and informal aspects, which might also be extended as a means to identify and design the social contexts where decisions are made or considered [35]. In the context of public policies, this kind of analysis helps the understanding of the process, not just for the analyst but also for everyone involved [13].

Nordström et al. ([36]) carried out a study of the strengths and weaknesses of an integrated approach of PA and MCA. They considered five stages for an integrated approach: stakeholder analysis, structuring of the problem, generation of alternatives, elicitation of preferences, and ranking of alternatives. This integrated assessment framework follows recent works carried out by Corral Quintana ([13]), among others. It uses an approach based on the relevance of extended or social participatory assessments [16,17]. Guimarães Pereira and Corral Quintana [16] discuss the importance of involving stakeholders in assessment processes, since "governance processes require community involvement in policy and decision-making" [16] (p. 10). In the same manner, Munda [17] discussed the role of social multi-criteria approaches while assessing environmental issues, emphasizing the need for these kinds of approaches for policy issues involving the integration of various and conflicting points of view. Other authors, more recently, have proposed other participatory assessment frameworks; this is the case with Macharis et al. [37], who suggest a multi-actor, multi-criteria analysis consisting of the inclusion of stakeholders in decision-making along with MCA methods as a tool to support sustainable decisions.

MCA is an appropriate tool for dealing with problems that involve multiple dimensions or criteria. Power relations, hidden interests, cultural constraints, and social participation are becoming more and more relevant in environmental policy and economic analyses [38]. These values are therefore the rule rather than the exception in land-use planning [39]. As a consequence, taking into account incommensurable dimensions using a scientific language becomes necessary [17]. It means that the rational choice is not only a technical matter but also involves important social values, which need to be protected [40]. Hence, using methods that are able to consider these different types of information is crucial $[16,39]$.

Consequently, the ability of MCA to manage qualitative information means it is an important tool for managing environmental conflicts [41]. In fact, MCA allows analysts to use qualitative and quantitative data at the same time, providing the possibility of including social values in the assessment $[42,43]$.

Our methodology is based on an integrated model of participation of stakeholder communities and a multi-criteria analysis to plan the use of forest tracks on the island of Tenerife. The assessment is structured in four phases: (a) Institutional Analysis; (b) Participatory Processes; (c) Multi-criteria Assessment; and (d) Conflict Analysis (see Figure 1). In the first phase, two activities were performed: 
an institutional analysis beginning with a review of the last 15 years of the main press on the island of Tenerife, and two rounds of interviews. Reviewing legislation, local and regional press articles allowed a first approximation of the social and political context of forest track use in Tenerife and the stakeholders that have been related to the issue in the past and currently. In this sense, it facilitates an evolutionary analysis of the role and positions of each stakeholder, providing a map of the relevant stakeholders and their positions (see Table 2) to be used in a later stage when analyzing possible stakeholder coalitions. This kind of press analysis follows previous work by Corral Quintana and Gamboa and Munda ([13,29]). Corral Quintana ([13]) stated that this exercise is worthwhile in order to have an extensive and a more balanced vision of the problem-extensive because the same issue is presented by different stakeholders and therefore reflects diverse perspectives. It may also be more balanced because different press journals narrate the issue in different ways depending on both their ideology and their scale (local, regional, or national). 
Table 2. Stakeholder communities according to their area of action and type of activity.

\begin{tabular}{|c|c|c|c|c|c|c|}
\hline \multicolumn{7}{|c|}{ Stakeholder Communities } \\
\hline $\begin{array}{l}\text { Type of activity } \\
\text { Area of action }\end{array}$ & $\begin{array}{l}\text { Decision- } \\
\text { makers }\end{array}$ & $\begin{array}{l}\text { Motorized } \\
\text { Sports }\end{array}$ & $\begin{array}{l}\text { Non-motorized } \\
\text { sports }\end{array}$ & $\begin{array}{c}\text { Surveillance } \\
\text { Safety/emergencies and rescue }\end{array}$ & Firms & Others \\
\hline Local & $\begin{array}{l}\text { Tenerife } \\
\text { island council } \\
\text { Town halls }\end{array}$ & $\begin{array}{l}\text { four-wheel- } \\
\text { drive vehicles } \\
\text { Motorbikes } \\
\text { Quad bikes }\end{array}$ & $\begin{array}{l}\text { Horse-riders } \\
\text { Mountaineers } \\
\text { Cyclists } \\
\text { Triathletes } \\
\text { Hikers } \\
\text { Hunters } \\
\end{array}$ & $\begin{array}{l}\text { Environmental agents } \\
\text { BRIFOR (forest fire brigade } \\
\text { prevention and extinguishing) }\end{array}$ & $\begin{array}{c}\text { Private firms } \\
\text { (forestry workers) } \\
\text { Private firms (tourism) } \\
\text { Pine-needle gatherers } \\
\text { Bee-keepers } \\
\text { Water management }\end{array}$ & $\begin{array}{c}\text { Experts } \\
\text { Recreational area users } \\
\text { Farm owners } \\
\text { Forest residents }\end{array}$ \\
\hline Regional & $\begin{array}{l}\text { Canarian } \\
\text { government }\end{array}$ & & & $\begin{array}{l}\text { Safety and emergency } \\
\text { committee of the Canarian } \\
\text { government Emergency and } \\
\text { security coordination } \\
\text { center } 112\end{array}$ & & \\
\hline National & & & & $\begin{array}{c}\text { Land army } \\
\text { SEPRONA (nature } \\
\text { protection service) } \\
\end{array}$ & $\begin{array}{l}\text { Public sector firms } \\
\text { (forestry work) }\end{array}$ & $\begin{array}{l}\text { PROFOR (association } \\
\text { of forestry professionals } \\
\text { in Spain) } \\
\end{array}$ \\
\hline
\end{tabular}




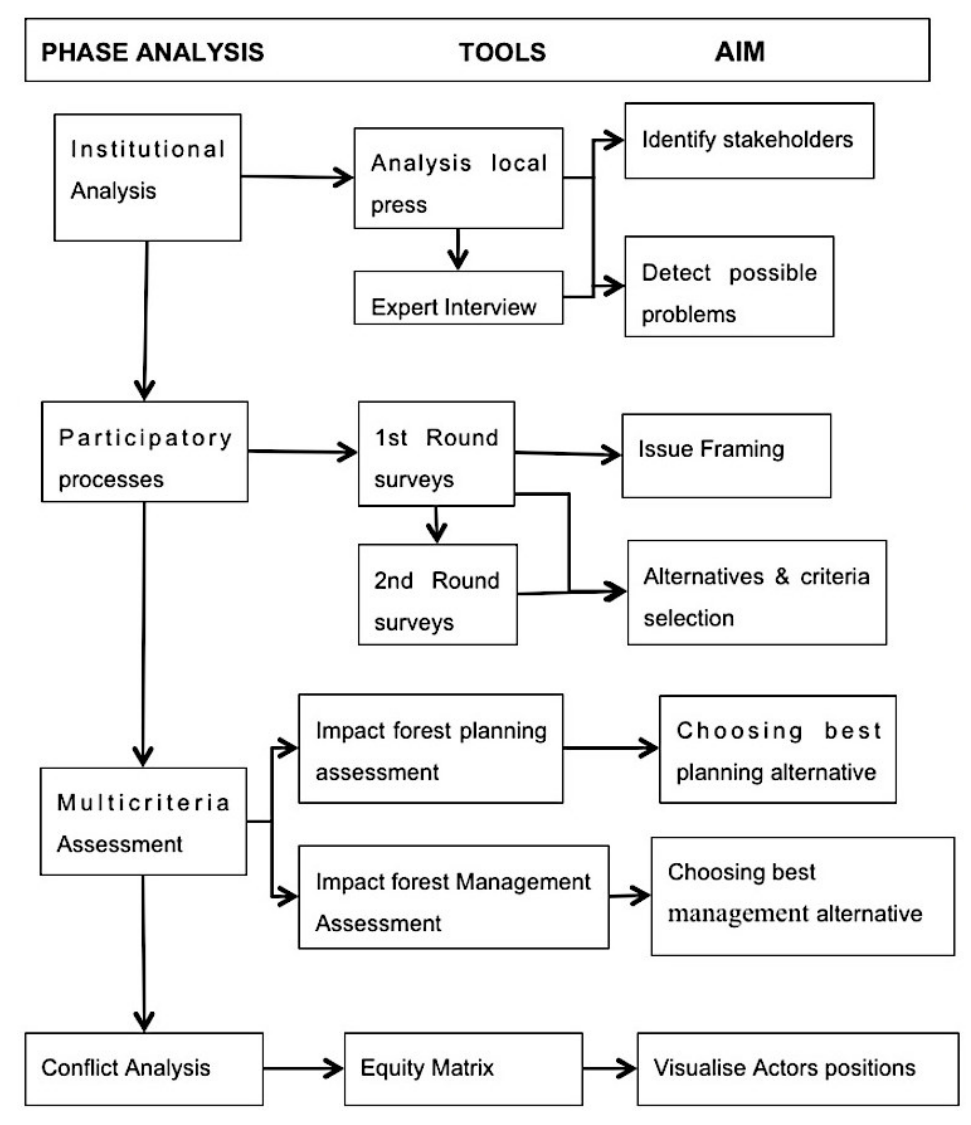

Figure 1. Integrated assessment methodology for forest issues.

The review was followed by various interviews with four experts in forest planning. Following the approach of Corral Quintana ([13]), the analyst played a passive role during the interviews; the analyst's main aim was to collect the greatest possible information about the problem under study. Another objective of this institutional analysis consisted of identifying the stakeholders involved in the issue, as well as detecting likely problems related to the case.

The experts were asked their opinions about the forest issue in Tenerife (i.e., general overview, key characteristics, impacts and effects, policy alternatives, etc.). Together they were also invited to provide a list of stakeholders involved. A second round of interviews was directed at those stakeholders identified during the first set of interviews. Similarly, they were asked about their concerns about the transport issue as well as about any other stakeholder involved in the process. So it was assured that all relevant stakeholders and their positions were clearly elicited, based on two criteria: (a) considering the most relevant stakeholders who have been involved in the debate on forest and sustainable use of natural resources in Tenerife during the last 20 years; and (b) taking into account the overall picture of transport on Tenerife.

Once framing information had been gathered, participative processes were carried out. There were two rounds of surveys, involving 188 people (37 decision-makers; 17 motorized sports groups; 29 non-motorized sports groups; 29 surveillance, safety, emergency, and rescue personnel; 42 businesses; and 34 others). In the first surveys, information related to forest planning and management was obtained, providing a preliminary set of assessment criteria and the majority of the alternatives used in the latter assessment. With the information from the second survey, the list of alternatives was completed. The reason for carrying out surveys instead of meetings arose from the 
data obtained in institutional analysis phase: this information indicated that a conflictive issue was being dealt with. This was elicited from several press articles in which the population expressed their disagreement with the access regulations to the forest.

Following the definition of alternatives and assessment criteria, the Novel Approach to Imprecise Assessment and Decision Environments (NAIADE) method (NAIADE has been applied in different case studies, such as water management [14,30], air pollution [13], wind farm location [29] and forest planning [44-46]) was selected from among the different MCA approaches. This multi-criteria method allows deterministic, stochastic, or diffuse measures of behavior of an alternative related to criteria through an assessment matrix or impact matrix.

A multi-criteria assessment approach was chosen due to its simplicity and its capacity to approximate the way human mind expresses and synthesizes preferences when faced with multiple contradictory decision perspectives [17]. NAIADE belongs to the wider family of outranking methods, details of which are discussed in Munda [17,45]. This method can incorporate fuzzy numbers in its calculations to deal with inexact information; this is an advantage when dealing with forest issues [47-49]. NAIADE also includes the possibility of using different types of measurement, including crisp (e.g., [1,20,34]), stochastic (e.g., probability functions), fuzzy (e.g., ambiguity of information), or linguistic information (e.g., good, not so good, bad) to evaluate the performance of alternatives.

Two types of assessment are possible with NAIADE [45]. First, an assessment of scores assigned to the criteria in each planning alternative can be made, namely an impact matrix. Secondly, a social equity matrix can be created, which analyses conflicts encountered among different groups and the possibility of forming coalitions, i.e., groups who would support the same option.

During the last 20 years NAIADE has been applied from different perspectives in different studies related to environmental issues, e.g., [50]. NAIADE has been implemented from a more technocratic perspective, with the researchers being in charge of defining alternatives and criteria, and developing and assessing the impact matrix. In some cases such as Corral Quintana [13] and Paneque et al. [15], NAIADE was applied within participatory frameworks in which stakeholders were involved in the assessment process, either validating results, as in the first article, or involving them in the definition of criteria and alternatives and the development of the assessment as Paneque et al. [15] proposed.

De Marchi et al. explored the possibilities of NAIADE to deal with natural resource management, specifically water-related issues, due to its potential to use qualitative information as well as to develop conflict analyses between stakeholders [14]. Paneque et al. [15] have also applied this method to handle water management issues, highlighting NAIADE's capacity to cope with uncertain data and to provide a framework for communication among stakeholders. Corral Quintana [13] has pointed out that NAIADE is a flexible and robust tool to explore air pollution issues, since the information, and the results can be presented in a transparent way to be fully understood by stakeholders. Moreover, Corral Quintana [13] has also highlighted that NAIADE allows analysts to explore the power relationships between stakeholders, and so have a clearer perspective of governance. The ability to use uncertain information, as well as deal with the complexity of the options that decision-makers may be interested in, has also been mentioned when dealing with the energy and environmental performance of different transport technologies [50] and forest reforestation [51]. 
Finally, NAIADE's ability to manage mixed information, i.e., qualitative and quantitative, is convenient for integrated coastal management [52]. The capability of using uncertain data for environmental management is also recurrent $[15,50,51,53]$.

However, some criticism of NAIADE can be found, such as that made by Garmendia et al. and Buchholz et al. [52,54]. Garmendia et al. mentioned that NAIADE's characteristic of not weighting criteria is potentially problematic, since some dimensions or criteria may be considered more important than others [52]. Nevertheless, differential weighting is not always required due to the fact that all dimensions of the issue under study are considered equally important [15].

In the following sections, the implementation process of this integrated assessment approach will be discussed, followed by the analysis of results. Finally, the conclusions and major findings will be presented.

\section{Results from Participatory Forest Planning and Management Assessments in Tenerife}

In the first phase of this study, an institutional analysis was conducted to detect the stakeholder communities involved and their concerns and positions related to the issue of forest access. It was based on a historical review and analysis of the past 15 years of press articles. This framing process was complemented by interviews carried out with several experts in the field. As a result, the most relevant stakeholders involved in the process were revealed, together with their positions and mechanisms of interaction. Six groups were identified according to the area and area of activity they carried out (see Table 2): (a) decision-makers; (b) motorized sports group; (c) non-motorized sports groups; (d) surveillance, safety, emergency, and rescue personnel; (e) businesses; and (f) others.

Following Nordström et al. and Antunes et al. [36,55]—on the need for early participation in these types of processes - two sets of interviews were carried out with stakeholders. The first one aimed at gathering information about stakeholders' roles with regard to forest planning and management activities, and their perceptions about other stakeholders' points of view. In this first survey, they were also asked about the main forest issues on the island and their concerns regarding past and present planning and management strategies.

From these interviews, it is worth noting that over half $(64.5 \%)$ of interviewees knew about the regulations on motorized traffic on forest tracks in Tenerife. Likewise, 97\% of those who stated they did not know or knew very little were still aware that there were some restrictions on motorized transport on these tracks.

Interviewees' opinions regarding the aims of these regulations were very diverse. The overall perception of the different groups regarding the regulations was of "rejection" of these regulations. In answer to "What have been the perceptions of different population segments (associations, sports people, private firms) about the implementation of these regulations?" $39 \%$ of the answers were rejections of them. This generalized rejection of the regulations does not bode well for peaceful co-existence in the forest; rather, it could well aggravate any existing problems. Overall, 24.1\% suggested that the regulatory process and implementation needed improving (see Figure 2). In addition, $28.6 \%$ of people answering that the regulations "do not contribute" to the conservation of the forests in Tenerife highlighted the lack of participative processes (information, awareness) (see Figure 3). 


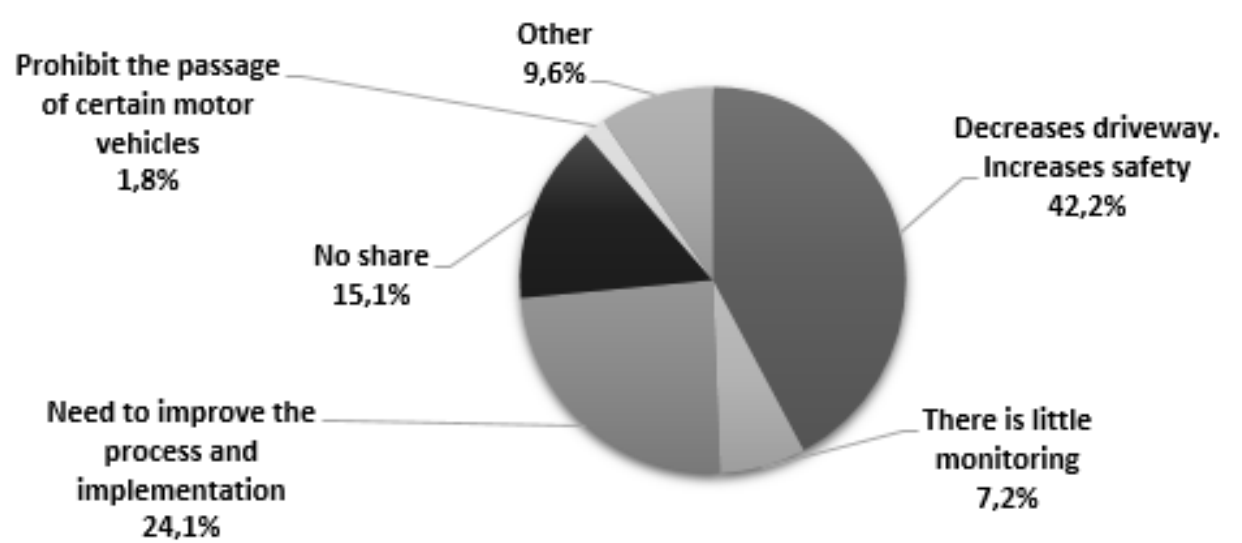

Figure 2. Interviewees' opinions about the forest regulations.

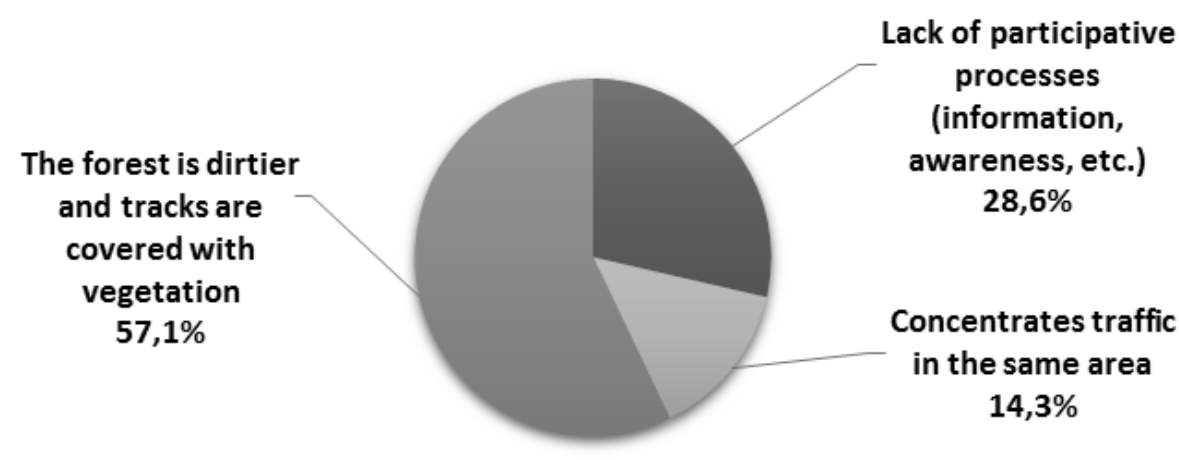

Figure 3. Interviewees who affirm the regulations do not contribute to the island's forest conservation.

Although "rejection" is clear, there are, however, indications that this feeling could be minimized. In answer to the question "What is your opinion of the regulations?" $24.1 \%$ of respondents indicated that they needed improving, with $42.5 \%$ of those coming from the "decision-makers" Group. This situation, in which the decision-makers themselves recognize the need to improve the decision-making process and implementation of regulations, is very advantageous to initiate changes that could minimize or solve this feeling of "rejection." The fact that decision-makers are aware of the problem should facilitate participative processes and dialogue.

During the second interview, a dialogue was established with the interviewees with the idea of proposing different alternatives to the issues discussed. During this dialogue two groups of alternatives emerged, some related to managerial issues (i.e., the use of prohibited areas, the improvement of surveillance and access, assistance points and improvement of infrastructures, etc.) and others related to planning aspects (one-way system vs. restricted to emergencies vs. unrestricted circulation, etc.) as represented in Table 3. 
Table 3. Alternatives in forest planning and management.

\begin{tabular}{cc}
\hline Management Alternatives & Planning Alternatives \\
\hline Limit use by areas. & Traffic circulation restricted to emergencies \\
Improve surveillance and control of access. & Unrestricted traffic circulation. \\
Improve infrastructures. & One-way systems. \\
Meeting and assistance points. & Pre-paid traffic circulation charge \\
Rubbish collection points. & Do not do anything; hereafter known as "BAU." \\
\hline
\end{tabular}

Once results from the two surveys were analyzed, it was decided to perform two assessment processes as some alternatives had more management characteristics, whereas others were more linked to planning issues. Initially, this study aimed at tackling a clear problem of planning the use of forest tracks, but as interviews with stakeholders progressed a parallel problem began to appear. As well as planning issues, interviewees expressed concerns about forest management. In this context, it was decided to modify the initial narrower objective to include a forest management issue as part of the assessment process. This led to the third phase in which two multi-criteria assessments were carried out: one for the planning alternatives and the other for management ones.

The interviewees were also asked to produce a set of criteria to assess the defined alternatives. An initial list of criteria was presented to facilitate the selection process, but this list was, in each case, modified with interviewees' own perceptions, leading to a set of economic, social, environmental, and institutional dimensions.

As for assessment criteria, these arose from the perceptions of stakeholders using open questions. However, in many cases, the opinions voiced were not specific assessment criteria but more like attributes. These were then specified into criteria that could be used to assess forest planning and management questions.

Together, other criteria were included such as introduced/threatened species, effects on agriculture, maintaining traditions, functionality and state of recreational areas, evacuation during fires, time period of action, social acceptance, etc. These were compiled from the literature on forest planning in order to allow the assessment of complementary aspects to those presented by stakeholders. The criteria used to assess both planning and management alternatives are presented in Table 4.

Table 4. Criteria to assess both planning and management alternatives.

\begin{tabular}{ccc}
\hline Dimensions & Forest Planning Alternatives & Forest Management Alternatives \\
\hline & Effects on erosion & Effects on erosion \\
ENVIRONM & Oxygenation & Effects on landscapes and aesthetics \\
ENTAL & Emission of pollutants & Oxyenation \\
& Particles and dust in the air & Dust particles in the air \\
& Effects on the water cycle & Effects on the water cycle \\
\hline
\end{tabular}


Table 4. Cont.

\begin{tabular}{ccc}
\hline Dimensions & Forest Planning Alternatives & Forest Management Alternatives \\
\hline & Economic cost & Economic cost \\
& Effects on employment & Effects on employment \\
& Effects on other productive activities & Effects on other productive activities \\
(leisure, services, quad bike sales) & (leisure, services, quad bike sales) \\
Effects on agriculture & Accessibility \\
SOCIOECON & Environmental awareness & Maintaining traditions \\
OMIC & Accessibility & Functionality and state of recreational areas \\
& Maintaining traditions & Opportunities to do leisure, sport, and \\
& Functionality and state of recreational areas & health activities \\
& Opportunities to do leisure, sports, & For traffic circulation \\
health activities & State of forest tracks \\
SOCIOECON & For traffic circulation & Accessibility for emergency services \\
OMIC & State of forest tracks & Evacuation during fires \\
INSTITUTIO & Evacuation during other emergencies & Evacuation during other emergencies \\
NAL & Time period of actions & Time period of actions \\
& Social acceptance & Social acceptance \\
\hline
\end{tabular}

\section{Integrated Assessment of Forest Planning and Management Alternatives}

Alternatives and the assessment criteria were elaborated and two impact matrices were built. The horizontal axis of the impact matrices corresponds to the alternatives, while on the vertical axis the assessment criteria are presented (see Tables 5 and 6). Each cell reflects how the alternative is influenced qualitatively by the selected criterion, based on the information from the reviewed scientific literature and the experts and stakeholders' opinions. Elicited knowledge was incorporated into the matrices applying a qualitative scale of five linguistic categories (see Table 7).

Table 5. Impact matrix: Planning alternatives.

\begin{tabular}{cccccc}
\hline & \multicolumn{5}{c}{ Alternatives } \\
\cline { 2 - 6 } Assessment Criteria & BAU & $\begin{array}{c}\text { Traffic } \\
\text { Circulation } \\
\text { Restricted to } \\
\text { Emergencies }\end{array}$ & $\begin{array}{c}\text { Unrestrict- } \\
\text { ed Traffic } \\
\text { Circulation }\end{array}$ & $\begin{array}{c}\text { One-Way } \\
\text { System on } \\
\text { Forest Tracks }\end{array}$ & $\begin{array}{c}\text { Pre-Paid } \\
\text { Traffic } \\
\text { Circulation } \\
\text { Charge }\end{array}$ \\
\hline Effects on erosion & Bad & Good & Very Bad & Bad & Good \\
Effects on landscapes and aesthetics & Bad & Bad & Bad & Good & Bad \\
Oxygenation & Moderate & Very Good & Very Bad & Moderate & Good \\
Emission of pollutants & Bad & Good & Very Bad & Moderate & Good \\
Particles and dust in the air & Bad & Good & Very Bad & Bad & Good \\
Effects on water cycle & Moderate & Good & Bad & Moderate & Good \\
Introduced/Threatened Species & Bad & Moderate & Very Bad & Bad & Good \\
Economic Cost & Good & Bad & Very Bad & Good & Bad \\
Effects on employment & Good & Very Bad & Good & Bad & Bad \\
\hline
\end{tabular}


Table 5. Cont.

\begin{tabular}{|c|c|c|c|c|c|}
\hline \multirow[b]{2}{*}{ Assessment Criteria } & \multicolumn{5}{|c|}{ Alternatives } \\
\hline & BAU & $\begin{array}{c}\text { Traffic } \\
\text { Circulation } \\
\text { Restricted to } \\
\text { Emergencies }\end{array}$ & $\begin{array}{l}\text { Unrestrict- } \\
\text { ed Traffic } \\
\text { Circulation }\end{array}$ & $\begin{array}{c}\text { One-Way } \\
\text { System on } \\
\text { Forest Tracks }\end{array}$ & $\begin{array}{c}\text { Pre-Paid Traffic } \\
\text { Circulation } \\
\text { Charge }\end{array}$ \\
\hline Effects on other productive activities & Good & Very Bad & Good & Good & $\mathrm{Bad}$ \\
\hline Effects on agriculture & Good & Very Bad & Moderate & $\mathrm{Bad}$ & Very Bad \\
\hline Environmental awareness & $\mathrm{Bad}$ & Moderate & Very Bad & Moderate & Good \\
\hline Accessibility & Good & Very Bad & Very Good & $\mathrm{Bad}$ & $\mathrm{Bad}$ \\
\hline Maintaining traditions & Bad & Very Bad & Very Good & $\mathrm{Bad}$ & $\mathrm{Bad}$ \\
\hline $\begin{array}{l}\text { Functionality and state of recreational } \\
\text { areas }\end{array}$ & Good & Moderate & Moderate & Moderate & Moderate \\
\hline $\begin{array}{l}\text { Opportunities to do leisure, sports, } \\
\text { etc. }\end{array}$ & Good & Very Bad & Very Bad & Moderate & Good \\
\hline Traffic circulation & Good & Very Good & Very Bad & Good & Moderate \\
\hline State of tracks & Good & $\mathrm{Bad}$ & Very Bad & Moderate & Good \\
\hline Accessibility for emergency services & $\mathrm{Bad}$ & Very Bad & Good & $\mathrm{Bad}$ & Moderate \\
\hline Evacuation during fires & Bad & Good & Very Bad & Very Bad & Good \\
\hline Evacuation during other emergencies & $\mathrm{Bad}$ & Good & Very Bad & Very Bad & Good \\
\hline Time period of action & $\begin{array}{c}\text { Mode } \\
\text { rate }\end{array}$ & Very Good & Very Good & $\mathrm{Bad}$ & Very Bad \\
\hline Social acceptance & $\mathrm{Bad}$ & Very Bad & Good & $\mathrm{Bad}$ & $\mathrm{Bad}$ \\
\hline
\end{tabular}

Table 6. Impact Matrix: Forest Management Alternatives.

\begin{tabular}{cccccc}
\hline & \multicolumn{3}{c}{ Alternatives } & & Improve \\
\cline { 2 - 6 } Assessment Criteria & $\begin{array}{c}\text { Limit Use } \\
\text { by Areas }\end{array}$ & $\begin{array}{c}\text { Surveillance } \\
\text { and Control } \\
\text { of Access }\end{array}$ & $\begin{array}{c}\text { Improve } \\
\text { Infrastructures }\end{array}$ & $\begin{array}{c}\text { Assistance } \\
\text { and Meeting } \\
\text { Points }\end{array}$ & $\begin{array}{c}\text { Rubbish } \\
\text { Collection } \\
\text { Points }\end{array}$ \\
\hline Effects on erosion & Good & Very Good & Very Good & Moderate & Moderate \\
Effects on landscapes and aesthetics & Good & Good & Very Good & Moderate & Good \\
Oxygenation & Good & Good & Moderate & Moderate & Moderate \\
Emission of pollutants & Good & Good & Moderate & Moderate & Moderate \\
Particles and dust in the air & Good & Good & Good & Moderate & Moderate \\
Effects on water cycle & Good & Good & Very Good & Moderate & Moderate \\
Economic Cost & Good & Very Bad & Very Bad & Bad & Bad \\
Effects on employment & Moderate & Very Good & Very Good & Good & Good \\
Effects on other productive activities & Good & Bad & Very Good & Good & Good \\
Accessibility & Bad & Very Bad & Very Good & Moderate & Moderate \\
Maintaining traditions & Bad & Bad & Good & Good & Good \\
Maintenance of recreational areas & Good & Good & Very Good & Moderate & Very Good \\
Opportunities to do leisure, sports, etc. & Very Good & Very Good & Very Good & Very Good & Very Good \\
Traffic circulation & Very Good & Very Good & Good & Moderate & Moderate \\
State of repair of tracks & Good & Good & Very Good & Moderate & Moderate \\
Accessibility for emergency services & Good & Good & Very Good & Very Good & Moderate \\
Evacuation during fires & Good & Very Good & Very Good & Good & Moderate \\
Evacuation during other emergencies & Good & Very Good & Very Good & Good & Moderate \\
Time period of actions & Very Bad & Bad & Bad & Good & Good \\
Social Acceptance & Good & Good & Very Good & Good & Good \\
\hline
\end{tabular}


Table 7. Scale of linguistic categories used during assessment.

\begin{tabular}{c}
\hline Linguistic Categories Used \\
\hline Very good \\
Good \\
Moderate \\
Bad \\
Very bad \\
\hline
\end{tabular}

Once the impact matrices were populated, the NAIADE multi-criteria method was used to provide a ranking of alternatives for both planning and management issues, respectively (see Figure 4). Figure 4 shows a ranking of alternatives from the best to the worst, according to the selected evaluation criteria.

Regarding planning assessment results, the best alternative was E, which corresponds to traffic circulation by a pre-paid charge. Alternatives A (BAU: maintain current situation) and B (Traffic circulation restricted to emergencies) are the next best ones in the ranking, both at the same level. Finally, there are alternatives C (Unrestricted traffic circulation) and D (one-way system on forest tracks) at the bottom of the ranking.

Forest planning issue

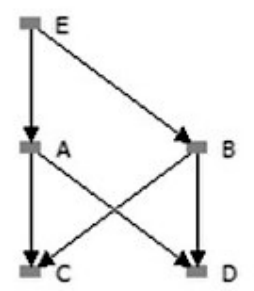

Forest management issue

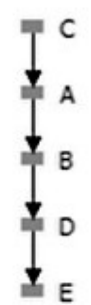

Alternatives:

A. BAU

B. Traffic restricted to emergencies

C. Unrestricted traffic circulation

D. One-way system on forest tracks

E. Traffic circulation by a pre-paid charge
Alternatives:
A. Limit Use by Areas
B. Better surveillance and Access control
C. Improve Infraestructures
D. Assistance and Meeting Points
E. Rubbish Collection Points

Figure 4. Ranking of planning and management alternatives.

The majority of the environmental criteria favored alternative E (pre-paid charge for traffic circulation); in fact, approximately $90 \%$ of these criteria were assessed as being "good." Regarding alternative A, identified as "BAU: maintain current situation," the socio-environmental criteria were those responsible for its position in the ranking; slightly under $65 \%$ of these criteria were assessed as being "good." At the same position as A is alternative B, which corresponds to "Traffic Circulation restricted to emergency use." The assessment of environmental criteria favored this result, since almost $90 \%$ of the criteria from this group were considered as being "very good", "good" or "moderate." Regarding alternatives $\mathrm{C}$ and $\mathrm{D}$, at the bottom of the ranking, alternative $\mathrm{C}$ received the worst 
assessment for socioeconomic and environmental criteria, whereas alternative D received low rankings in all three dimensions.

With these results, should the best-considered alternative, "pre-paid charge for traffic circulation," be implemented? It is likely that the number of vehicles using the forest would decrease, since having to pay would lead to some individuals deciding not to use their vehicles in the forest. This would, in turn, lead to a reduction in pollution (noise, exhaust fumes, and dust), contributing to the conservation of the forest environment. On the other hand, it is a decision that would not be well received by some segments of the population, as discussed in the next section.

It is worth highlighting that implementing the second-place alternative in the ranking, "Traffic circulation restricted to emergency use," prevents any other alternative from being adopted except a "One-way system for forest tracks." By restricting use to emergencies, there is no sense, for example, in making a charge for access.

From these results, it can be concluded that a viable combination of alternatives would be a "Pre-paid charge for traffic" and "Maintaining current situation," with the variant that the charge is initially applied to tourists, without ruling out the possibility of subsequently applying it to residents, too. The aim of this would be to contribute to the conservation of the forest environment on the island, which would be beneficial for the coexistence of all the stakeholder communities involved.

With regard to the alternatives linked to management (Figure 4), the best alternative is clearly C, which involves "Improving Forest Infrastructures." This is followed by alternative A, which aims at "Limiting Use to Certain Areas," and then by alternative B, which establishes "Better surveillance and control of access"; next comes D, which proposes "Assistance and Meeting Points." The alternative with the worst assessment was E, which establishes "Rubbish Collection Points."

Alternative C, "Improve Infrastructures," was the highest ranked according to socioeconomic and environmental criteria: $100 \%$ of environmental criteria were assessed as being "moderate," "good," or "very good," and $75 \%$ of the socioeconomic ones were in the "very good" category for this alternative. This result is not so striking given that, overall, interviewees affirmed the need to improve infrastructures in the forest environment, specifically an improvement in the state and maintenance of forest tracks. The second ranked alternative was "Limit Use by Areas"; environmental and socioeconomic criteria most favored this alternative with $100 \%$ of environmental variables being in the "good" category, and $83.3 \%$ of socioeconomic ones being "very good," "good," or "moderate."

Currently, Tenerife's Island Council is working on a network of tracks for bicycles and horses. This action would not necessarily be rejected by policy-makers, although it would involve using further participative processes with dialogue free from coercion to ensure that the results obtained were the most favorable for the conservation of the forest environment and for its users.

A sensitivity analysis was performed in order to elucidate conflicts among alternatives and objectives, and to test the robustness of the model [56,57]. Two different sensitivity analyses were carried out to evaluate the integrated assessment performed. On one hand, a technical sensitivity analysis was performed in order to assess the robustness of the model and the NAIADE impact matrix ranking of alternatives. In NAIADE the sensitivity analysis is done following Munda ([45]); it consists of changing the parameters defined by the operator (a and s parameters), also considering higher and lower crossover values and different operators: minimum, Zimermann-Zysno, and simple product. The crossover values are the points where the preference relation reaches a credibility index of 0.5 (where 
it begins to be sufficiently credible) and they were evaluated on the maximum and minimum distance. The results showed that the final evaluation discussed in previous sections is stable.

On the other hand, a so-called social sensitivity analysis (SSA) was performed. It consisted of a focus group session, in which, the different stakeholder groups were represented (in total 25 people attended the session). The actors involved in this SSA were selected through the implementation of an institutional analysis and they represent the different visions related to the forest issue at hand. Authors were very careful to include all actors related to the issue in order to have all the visions represented. Initially, they were asked about the criteria and alternatives selected, in order to know whether those characterized the issue at hand or, on the contrary, whether some relevant dimensions were either missing or ambiguous. This is considered a crucial analysis in order to validate the robustness of the assessment process, since we are facing a decision-making issue characterized by opposite positions and it cannot be considered a mere technocratic assessment, as pointed out by Guimarães Pereira and Corral Quintana [16]. Thus, the evaluation results are not a simple ranking of options, but are alternatives both reflecting stakeholders' opinions and affecting their interests. In that case, the socalled SSA is a way of forming spaces of dialogue among the actors involved. As a result of this focus group, the pertinence of these alternative and criteria was expressed.

\section{Discussion: Revisiting Assessment Results after Mapping Social Conflicts in Forest Planning and Management}

The resulting ranking of alternatives was based on the best scientific and social knowledge available. However, does it reflect the opinions of the stakeholders too?

Due to the evident tensions existing among the involved stakeholders, the previous assessment of the different policy alternatives is not enough to understand the political issue at hand. Together, an analysis of stakeholders' positions and perceptions was carried out, since the resulting knowledge was considered a useful insight for latter stages of policy implementation.

Based on the available qualitative and quantitative information, a consensus analysis was carried out. This analysis aims to identify those alternatives that could reach a certain degree of consensus among the different interest groups involved. On previous occasions, this analysis has been demonstrated to be useful to understand stakeholders' positions in several environmental conflicts, such as air pollution [13] and water issues [14,15].

The equity analysis starts with the creation of the equity matrix, which gives a linguistic indication of the interest group judgement for each of the alternatives. Semantic distance is also used in this case to calculate the similarity indexes among interest groups. A similarity matrix is then computed starting from the equity matrix. The Similarity matrix gives an index, for each pair of interest groups (i,j) of the similarity of judgement over the proposed alternatives (for a more detailed information about the mathematical algorithm applied to develop the dendrogram of coalitions, consult [58]).

In the following paragraphs, the opinions about the alternatives will be presented, through the development of the so-called social equity matrix. This matrix associates each alternative with stakeholders' viewpoints, both in the assessment of planning (see Figure 5) and management (see Figure 6) alternatives. Each figure represents the possible convergences of interests among 
different groups and identifies potential conflicts among different stakeholder groups and the possibility of forming coalitions [45].

The evaluation of the social equity matrix is carried out by NAIADE. It is based on an algorithm that is used to build a dendrogram of coalitions, i.e., possible group formations, which reflect the level of conflict among stakeholders. According to Munda, this procedure involves two steps: first, the definition of a discrete number of well-defined actions; and second, an evaluation of the impacts of management scenarios on different interest groups by means of linguistic variables [45]. The clustering algorithm indicates the groups whose interests are closer to the others. Results from the equity matrix presented in the dendrogram of coalitions reflect different possible group formations with different levels of credibility. The level of credibility, shown to the left of the dendrogram (Figure 5), determines the plausibility of a group forming a coalition. A higher value implies a major likelihood of forming a coalition among stakeholder communities $[13,15]$.

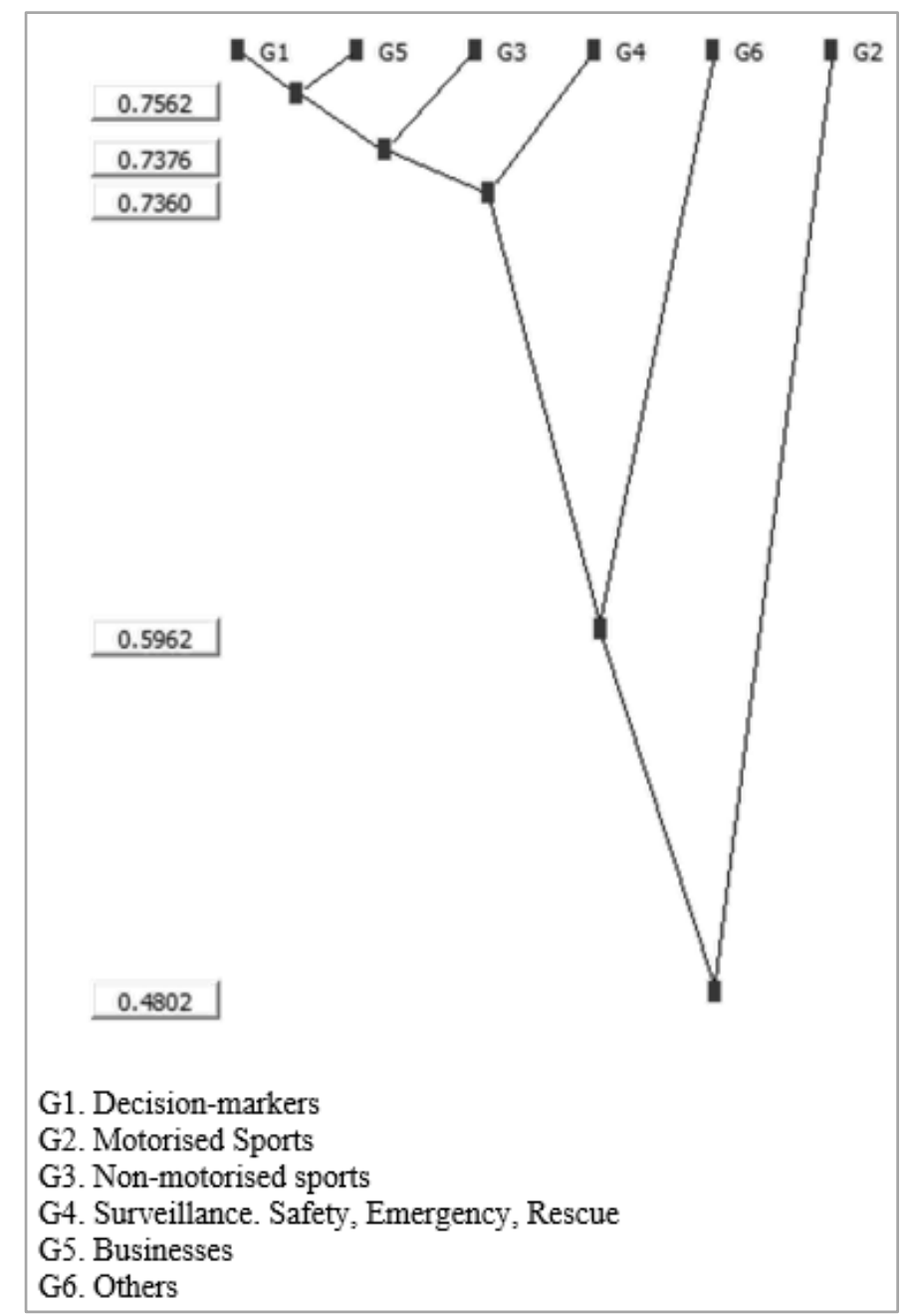

Figure 5. Dendrogram of stakeholder groups on the forest planning issue.

In Figure 5, "decision-makers" and business groups show the greatest similarity in interests. Just below are two close levels, which could lead to a coalition of stakeholder groups between "non-motorized sports" and "surveillance, safety, emergency, and rescue." This closeness is due to the combination of environmental, economic, and social interests being very similar. This does not 
happen, however, with the group "motorized sports," which, although converging on the downward line, has a combination of interests that are notably different to the others.

As a result of the forest planning assessment, "Pre-paid traffic charge" was considered the best alternative; however, although some politicians were in favor of a variant of this alternative, the proposed payment of 50 cents or even one euro - which the majority of tourists would pay to gain access to a forest environment on the island-was considered unacceptable for Tenerife's residents since the prevalent local opinion is that they should not have to pay for something they own.

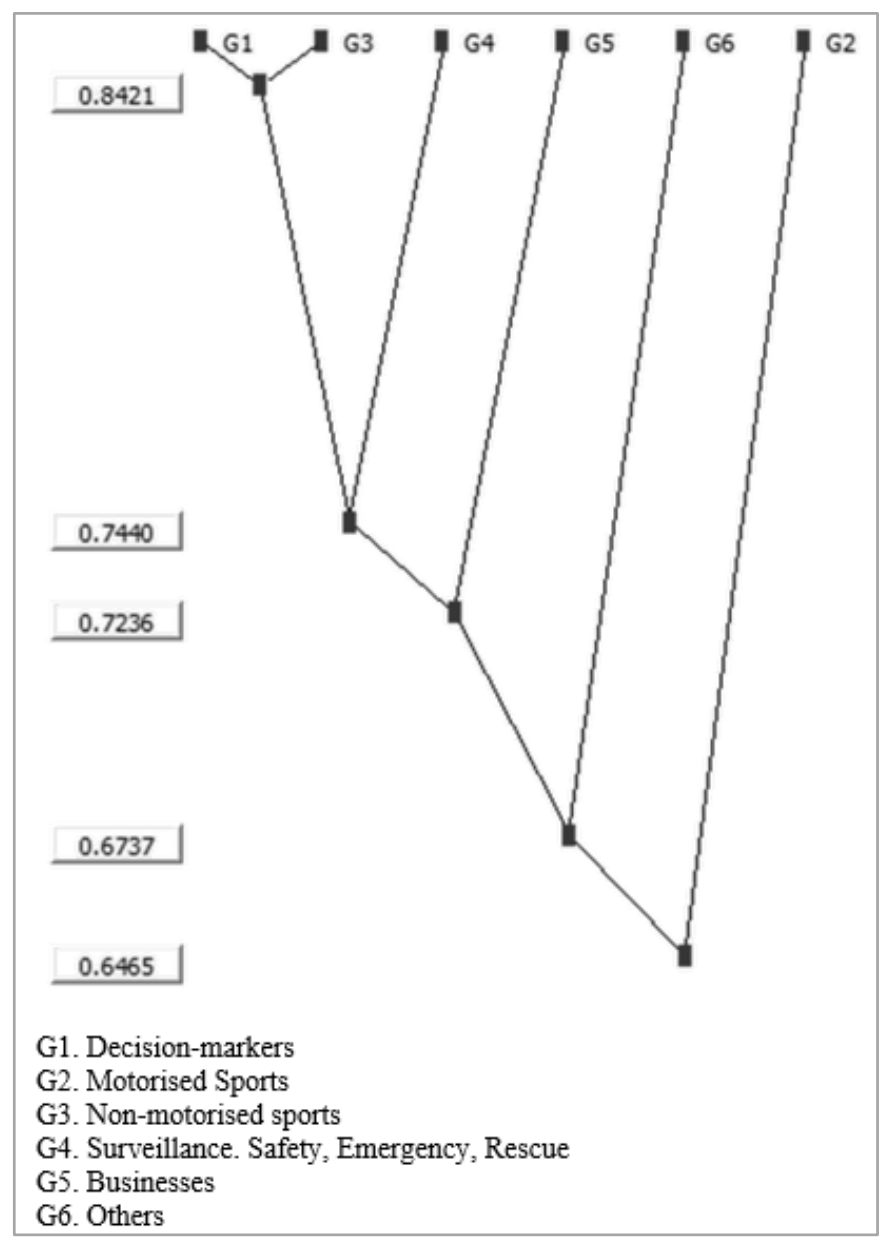

Figure 6. Dendrogram of stakeholder groups on forest management issue.

Due to this reticence about access payment, a combination of a pre-paid traffic charge with the alternative of maintaining the current situation for residents should also be taken into consideration by decision-makers. The joint implementation of these alternatives would both increase the monetary contribution to the conservation of the forest environment on the island and contribute to the more peaceful coexistence of different forest stakeholder communities.

With regard to coalitions, forest management "decision-makers" and "non-motorized sports" are the ones that have the greatest similarities in interests and could form a coalition (see Figure 6). Another feature of this figure is the existence of a division that clearly separates the positions of stakeholder groups, right where the group "surveillance, safety, emergency, and rescue" is located. This result reveals that those groups in the lower part of the figure have little in common with "decision-makers" and "non-motorized sports." For example, the "motorized sports" group, at the 
bottom of the figure, is not in favor of any restrictions on traffic circulation along forest tracks. In contrast to the results obtained in the planning analysis, the management one clearly shows the disparities between stakeholder groups in the dendrogram. This means that making decisions could be somewhat more complex owing to the lack of similarities in the interests of different groups.

This situation of social discrepancies in both cases should not be ignored in future decision-making processes regarding forest planning and management, as discussed in the conclusions below.

\section{Lessons Learned and Conclusions}

Following Nordström et al. and Antunes et al. [36,55], on early participation in environmental decision-making processes, the authors consider that stakeholder communities have felt excluded from these processes despite having really wanted to take part in elaborating regulations on the use of forest environments. This perception is one of the factors that might have caused the general feeling of rejection expressed by segments of the island's population regarding the regulations on motorized transport on forest tracks.

Sustainable forest planning implies the participation of stakeholder communities. However, environmental processes are complex [4-6], not only because of the multiple stakeholders involved but also because of the variety of criteria (economic, environmental, and social) to be considered. In this study, a large number of stakeholders were identified with, on occasions, conflicting interests. This was the case, for example, with motor vehicle users and people doing non-motorized sports. The overall perception of the latter group was that the noise and speed of the vehicles disturbed the quality of their visits to the forest.

The participation of stakeholders in the surveys enables crucial modifications to be made to the initial perception of the problem under study. The earlier hypothesis was the existence of a forest planning conflict in the use of forest tracks, but during the participatory framing process a hidden issue of forest track management emerged. This modified the subsequent assessment phase.

The application of multi-criteria methods, specifically the NAIADE method, allowed for the structuring and processing of the information obtained from social participatory techniques. [35]. However, even though social actors were involved from the beginning in the participatory multi-criteria analysis, this does not mean that they will agree with the assessment results. On the contrary, based on the existing evidence of long-term conflict among social actors, an analysis of the degree of acceptance of the different alternatives might be relevant to foresee how stable the alternatives might be.

In conflicting situations, the more prescriptive analysis of alternatives should be combined with a conflict analysis to ensure a better understanding of the policy implications of implementing the chosen alternatives, and even to provide new policy options when discussing the alternatives regarding forest planning assessment. In fact, in certain situations it is impossible to achieve a solution that maximizes all criteria; therefore, under these circumstances, it is necessary to find compromises that can minimize conflict. In this study, such a solution is evident at the intersection between the two assessments in the impact and equity matrixes performed with NAIADE, allowing the identification of social alliances and providing further insight into possible conflicts with the implementation of control measures. The results of the social equity matrix in this study demonstrate that there is social conflict 
due to diverging interests and positions over which management alternative to follow. As in previous studies $[4,13,14]$, we have argued that this is a situation where an escape from value judgments is impossible.

\section{Acknowledgments}

The authors wish to acknowledge the Canarian Agency for Research, Innovation and Information Society, which provided substantial funding to the University of La Laguna to make possible the publication of this article. (Co-funded by the European Social Fund-financing rate, 85\%.)

\section{Author Contributions}

Montserrat Acosta carried out the case study. Corral Quintana provided expertise in methodology and analysis of results. The article was improved by the contributions of all of the co-authors at various stages of the analysis and writing process.

\section{Conflicts of Interest}

The authors declare no conflict of interest.

\section{References}

1. Corral Quintana, S. A Quality Assurance Framework for Policy-making: Proposing a Quality Assurance Assistant Tool (QAAT). In Science for Policy. New Challenges, New Opportunities; Oxford University Press: New Delhi, India, 2009.

2. Lindblom, C.E. El Proceso de Elaboración de Políticas Públicas; Ministerio para las Administraciones Públicas: Madrid, Spain, 1991.

3. Kangas, J.; Kangas, A. Multiple criteria decision support in forest management-The approach, methods applied, and experiences gained. For. Ecol. Manag. 2005, 207, 133-143.

4. Munda, G. Métodos y procesos multicriterio para la evaluación social de las políticas públicas. Revista Iberoamericana de Economía Ecológica (REVIBEC); Universidad Nacional Autónoma de México: Michoacán, México, 2004; pp. 31-45.

5. Funtowicz, S.O.; Ravetz, J.R. La Ciencia Posnormal: Ciencia Con la Gente; Icaria Editorial: Barcelona, Spain, 1993.

6. Corral Quintana, S.; Funtowicz, S.; Munda, G. Planificación y Gestión Hídrica. Un ejemplo de evaluación multicriterial participativa. La Economía Ecológica: Una Nueva Mirada a la Ecología Humana; Centro de Estudios Superiores Universitarios, Universidad Mayor de San Simón: San Simón, Bolivia, 1999.

7. Buchy, M.; Hoverman, S. Understanding public participation in forest planning: A review. For. Policy Econ. 2000, 1, 15-25.

8. Díaz-Balteiro, L.; Romero, C. Making forestry decisions with multiple criteria: A review and an assessment. For. Ecol. Manag. 2008, 255, 3222-3241.

9. Mendoza, G.A.; Prabhu, R. Combining participatory modeling and multi-criteria analysis for community-based forest management. For. Ecol. Manag. 2005, 207, 145-156. 
10. Sheppard, S.R.J.; Meitner, M. Using multi-criteria analysis and visualisation for sustainable forest management planning with stakeholder groups. For. Ecol. Manag. 2005, 207, 171-187.

11. Vainikainen, N.; Kangas, A.; Kangas, J. Empirical study on voting power in participatory forest planning. J. Environ. Manag. 2008, 88, 173-180.

12. Funtowicz, S.; Strand, R. De la demostración experta al diálogo participativo. Rev. Iberoam. Cienc. Tecnol. Soc. 2007, 3, 97-113.

13. Corral Quintana, S. Una Metodología Integrada de Exploración y Comprensión de los Procesos de Elaboración de Políticas Públicas; Universidad de La Laguna: La Laguna, Spain, 2004.

14. De Marchi, B.; Funtowicz, S.; Lo Cascio, S.; Munda, G. Combining participative and institutional approaches with multicriteria evaluation. An empirical study for water issues in Troina, Sicily. Ecol. Econ. 2000, 34, 267-282.

15. Paneque Salgado, P.; Corral Quintana, S.; Guimaraes Pereira, A.; del Moral Ituarte, L.; Pedregal Mateos, B. Participative multi-criteria analysis for the evaluation of water governance alternatives. A case in the Costa del Sol (Malaga). Ecol. Econ. 2009, 68, 990-1005.

16. Guimarães Pereira, A.; Corral Quintana, S. From technocratic to participatory decision support systems: responding to the new governance initiatives. J. Geogr. Inf. Decis. Anal. 2002, 6, 95-107.

17. Munda, G. Social multi-criteria evaluation: Methodological foundations and operational consequences. Eur. J. Oper. Res. 2004, 158, 662-677.

18. Cabildo de Tenerife Plan Insular de Ordenación de Tenerife. 2011.

19. Consejería de Obras Públicas, Transportes y Política Territorial. Resolución de 16 de febrero de 2012, por la que se hace público el Acuerdo de la comisión de Ordenación del Territorio y Medio Ambiente de Canarias adoptado en la sesión celebrada el 30 de marzo de 2011, relativo a la aprobación de la memoria ambiental y aprobación definitiva y de forma parcial del Plan Rector de Uso y Gestión del Parque Natural de la Corona Forestal. 2012.

20. Gobierno de Canarias. Ley 11/1990, de 13 de julio, de Prevención del Impacto Ecológico. B.O.C. 92, de 23.7. 1990.

21. García Mesa, D.A. Los Aprovechamientos Forestales en la Segunda Mitad del Siglo XX; Quirantes González, F., Núñez Pestano, J.R., Eds.; Historia de los montes de Tenerife: La Laguna, Spain, 2011.

22. Quirantes González, F.; Núñez Pestano, J.R.; García Mesa, D.A.; Viña Brito, A. Los Montes de Tenerife a Través de su Historia; Servicio de Publicaciones, Universidad de La Laguna: La Laguna, Spain, 2011.

23. Cabildo de Tenerife Resolución R0000319624 de 14 de abril de 2011. Área de Sostenibilidad, Territorio y Medio Ambiente. Servicio Administrativo de Medio Ambiente. 2011.

24. Belton, V.; Stewart, T. Problem Structuring and Multiple Criteria Decision Analysis. Trends in Multiple Criteria Decision Analysis; Springer: New York, USA, 2010; pp. 209-239.

25. Ananda, J.; Herath, G. The use of Analytic Hierarchy Process to incorporate stakeholder preferences into regional forest planning. For. Policy Econ. 2003, 5, 13-26.

26. Kijazi, M.H.; Kant, S. Social acceptability of alternative forest regimes in Mount Kilimanjaro, Tanzania, using stakeholder attitudes as metrics of uncertainty. For. Policy Econ. 2011, 13, 242-257.

27. Kangas, A.S.; Kangas, J. Probability, possibility and evidence: approaches to consider risk and uncertainty in forestry decision analysis. For. Policy Econ. 2004, 6, 169-188. 
28. Kangas, A.S.; Kangas, J.; Lahdelma, R.; Salminen, P. Using SMAA-2 method with dependent uncertainties for strategic forest planning. For. Policy Econ. 2006, 9, 113-125.

29. Gamboa, G.; Munda, G. The problem of windfarm location: A social multi-criteria evaluation framework. Energy Policy 2007, 35, 1564-1583.

30. Paneque Salgado, P.; Corral Quintana, S.; Guimarães Pereira, Â.; del Moral Ituarte, L.; Pedregal Mateos, B. Actores sociales en la política de aguas: Evaluación participativa del abastecimiento de la Costa del Sol. Rev. Real Acad. Cienc. Exactas Fís. Nat. 2004, 98, 311-322.

31. Khadka, C.; Hujala, T.; Wolfslehner, B.; Vacik, H. Problem structuring in participatory forest planning. For. Policy Econ. 2013, 26, 1-11.

32. Kangas, A.; Saarinen, N.; Saarikoski, H.; Leskinen, L.A.; Hujala, T.; Tikkanen, J. Stakeholder perspectives about proper participation for Regional Forest Programmes in Finland. For. Policy Econ. 2010, 12, 213-222.

33. Mendoza, G.A.; Martins, H. Multi-criteria decision analysis in natural resource management: A critical review of methods and new modelling paradigms. For. Ecol. Manag. 2006, 230, 1-22.

34. Belton, V.; Stewart, T. Multiple Criteria Decision Analysis: An Integrated Approach; Springer Science \& Business Media: Dordrecht, The Netherland, 2002.

35. Corral Quintana, S.; Funtowicz, S. Cómo Afrontar La Problemática Compleja Del Agua; Ecología Política, Icaria: Barcelona, Spain, 1998; pp.111-117.

36. Nordström, E.; Eriksson, L.O.; Öhman, K. Integrating multiple criteria decision analysis in participatory forest planning: Experience from a case study in northern Sweden. For. Policy Econ. 2010, 12, 562-574.

37. Macharis, C.; Turcksin, L.; Lebeau, K. Multi actor multi criteria analysis (MAMCA) as a tool to support sustainable decisions: State of use. Decis. Support Syst. 2012, 54, 610-620.

38. Funtowicz, S.; Martinez-Alier, J.; Munda, G.; Ravetz, J. Information tools for environmental policy under conditions of complexity. Environmental Issues Series; European Environmental Agency: Copenhaguen, Denmark, 1999; pp. 1-34.

39. Nijkamp, P.; Rietveld, P.; Voogd, H. Multicriteria Evaluation in Physical Planning; North-Holland: Amsterdam, Holland, 1990.

40. Vatn, A. Institutions and the Environment; Edward Elgar: Cheltenham, UK; Northampton, MA, USA, 2005.

41. Beinat, E.; Nijkamp, P. Multicriteria Analysis in Land-Use Management; Kluwer Academic Press: Dordrecht, The Netherlands, 1998; Volume 9.

42. De Brucker, K.; Verbeke, A.; Macharis, C. The applicability of multicriteria-analysis to the evaluation of intelligent transport systems (ITS). Res. Transp. Econ. 2004, 8, 151-179.

43. Martinez-Alier, J.; Munda, G.; O’Neill, J. Weak comparability of values as a foundation for ecological economics. Ecol. Econ. 1998, 26, 277-286.

44. Etxano Gandariasbeitia, I.; Garmendia Oleaga, E.; Pascual, U.; Hoyos Ramos, D.; Díez López, M.Á.; Cadiñanos, J.A.; Lozano, P.J. Towards a Participatory Integrated Assessment Approach for Planning and Managing Natura 2000 Network Sites; Basque Centre for Climate Change/Klima Aldaketa Ikergai: Bilbao, Spain, 2012.

45. Munda, G. Multicriteria Evaluation in a Fuzzy Environment: Theory and Applications in Ecological Economics; Physica-Verlag: Amsterdam, Holland, 1995. 
46. Munda, G. Metodos y Procesos Multicriterio para la Evaluación Económico-Ambiental de las Políticas Públicas; Departamento de Economía e Historia Económica, Universidad Autónoma de Barcelona: Barcelona, Spain, 2002.

47. Avineri, E.; Prashker, J.; Ceder, A. Transportation projects selection process using fuzzy sets theory. Fuzzy Sets Syst. 2000, 116, 35-47.

48. Panou, K.; Sofianos, A. A fuzzy multicriteria evaluation system for the assessment of tunnels vis-à-vis surface roads: The WPMA case-Part II. Tunnel. Undergr. Space Technol. 2002, 17, 209-219.

49. Yeh, C.; Deng, H.; Chang, Y. Fuzzy multicriteria analysis for performance evaluation of bus companies. Eur. J. Oper. Res. 2000, 126, 459-473.

50. Brand, C.; Mattarelli, M.; Moon, D.; Calvo, R.W. STEEDS: A strategic transport-energy-environment decision support. Eur. J. Oper. Res. 2002, 139, 416-435.

51. Espelta, J.M.; Retana, J.; Habrouk, A. An economic and ecological multi-criteria evaluation of reforestation methods to recover burned Pinus nigra forests in NE Spain. For. Ecol. Manag. 2003, 180, 185-198.

52. Garmendia, E.; Gamboa, G.; Franco, J.; Garmendia, J.M.; Liria, P.; Olazabal, M. Social multi-criteria evaluation as a decision support tool for integrated coastal zone management. Ocean Coast. Manag. 2010, 53, 385-403.

53. Monterroso, I.; Binimelis, R.; Rodríguez-Labajos, B. New methods for the analysis of invasion processes: Multi-criteria evaluation of the invasion of Hydrilla verticillata in Guatemala. J. Environ. Manag. 2011, 92, 494-507.

54. Buchholz, T.; Rametsteiner, E.; Volk, T.A.; Luzadis, V.A. Multi criteria analysis for bioenergy systems assessments. Energy Policy 2009, 37, 484-495.

55. Antunes, P.; Santos, R.; Videira, N. Participatory decision making for sustainable development—The use of mediated modelling techniques. Land Use Policy 2006, 23, 44-52.

56. Tarantola, S. Global Sensitivity Analysis; The Primer, Wiley.: West Sussex, England, UK, 2008.

57. Menegolo, L.; Pereira, A. NAIADE-Manual; Joint Research Centre of the European Commission: Ispra, Italy, 1996.

58. Saltelli, A.; Ratto, M.; Andres, T.; Campolongo, F.; Cariboni, J.; Gatelli, D. Global Sensitivity Analysis: The Primer; John Wiley \& Sons: West Sussex, England, UK, 2008.

(C) 2015 by the authors; licensee MDPI, Basel, Switzerland. This article is an open access article distributed under the terms and conditions of the Creative Commons Attribution license (http://creativecommons.org/licenses/by/4.0/). 